\title{
Suicide and deliberate self-harm in Pakistan: a scoping review
}

\author{
Sualeha S. Shekhani ${ }^{1}$, Shagufta Perveen ${ }^{2}$, Dur-e-Sameen Hashmi', Khawaja Akbarr, Sara Bachani ${ }^{3}$ \\ and Murad M. Khan ${ }^{1 *}$
}

\begin{abstract}
Background: Suicide is a major global public health problem with more than 800,000 incidents worldwide annually. Seventy-five percent of the global suicides occur in low and middle-income countries (LMICS). Pakistan is a LMIC where information on suicidal behavior is limited. The aim of the review is to map available literature on determinants, risk factors and other variables of suicidal behavior in Pakistan.

Method: This study was based on Arksey and O'Malley's methodological framework of scoping review, combining peer reviewed publications with grey literature. Ten databases including Applied Social Sciences Index and Abstracts (ASSIA), Cochrane Trials Register (CRG), Cumulative Index to Nursing and Allied Health (CINAHL), National Library of Medicine Gateway (NLMG), ExcerptaMedica (EMBASE), National Library of Medicine's MEDLINE (PUBMED), PSYCHINFO, Social Science Citation Index and Science Citation Index (SCI) and Pakmedinet.com were searched from the beginning of their time frames until December 2016 using a combination of key terms. The inclusion criteria included studies of various study designs covering different aspects of suicidal behavior in English language.

Results: Six hundred and twenty three articles were initially retrieved from all ten databases. Two independent reviewers screened the titles and abstracts for relevance. One hundred and eighteen articles were read in full, out of which 11 were excluded because they did not fit the eligibility criteria. One hundred and ten articles, including two student theses and one report, were included in the final review. Most studies were descriptive in nature, with only three that used a case-control design. Majority of the studies were from urban areas, and addressed determinants rather than risk factors. Gender differences and age were predominantly reported, with more males committing suicide. Suicidal behavior was more common among individuals younger than 30 years of age. The three most common methods for suicides were hanging, poisoning and use of firearms. Mental illness as a risk factor for suicides was mentioned in only three studies.
\end{abstract}

Conclusions: This review is the first attempt to synthesize available literature on suicidal behavior in Pakistan. The evidence is limited, and calls for more robust analytical research designs, along with a focus on risk factors.

Keywords: Pakistan, Muslim, Suicidal behavior, Public health

\section{Background}

In 2012, an estimated 804, 000 deaths by suicide occurred worldwide, representing an annual global agestandardized suicide rates of 11.4 per 100,000 population (15.0 for males and 8.0 for females) [1]. Suicide is considered the second leading cause of death in people between the ages of 15 and 29 years worldwide [2]. Although the numbers and rates differ significantly between

\footnotetext{
* Correspondence: murad.khan@aku.edu

${ }^{1}$ Department of Psychiatry, Aga Khan University, Karachi, Pakistan

Full list of author information is available at the end of the article
}

countries, $75 \%$ of all global suicides occur in low and middle-income countries (LMICs) [1].

Research into suicidal behavior (which includes completed suicide, deliberate self-harm (DSH) and suicidal ideation) shows variations with respect to determinants, risk factors and motivations for such acts. Much of the research has been conducted in Western, industrialized countries where mental disorders appear to play a crucial role in suicidal behaviors, whereas in non- Western settings (particularly in South Asian cultures), interpersonal relationship problems appear to play a more critical role $[3,4]$. 
Reported rates of suicide in several Asian countries appear to be higher than the average global rates with only two countries (India and China) contributing more than $45 \%$ of the global suicides [5]. Although there has been a percentage decrease in the rates of both countries, the numbers still remain high at 258,075 and 120,730 respectively $[1,5]$. Pakistan is a low and middle income country with an estimated population of 200 million, making it the 6th most populous country in the world [6]. Ninety-seven percent of its population is Muslim and the Islamic religion plays an important role in peoples' daily lives [7]. Approximately $50 \%$ of its population is under the age of 25 years [6]. The country has four provinces (Punjab, Sindh, Balochistan and Khyber Pakhtunkhawa), several languages, cultures, sub-cultures, ethnicities and religious sects. Since its independence, the country has faced major challenges of an unstable political system and poor governance and the country's social and health indicators remain consistently poor [8]. Prevalence rates of common mental disorders (CMDs) put the figure as high as $34 \%$ [9].

Suicidal behavior remains an under-researched and under-studied subject in Pakistan [10]. Official mortality statistics on suicide are not available since they are not part of the national vital registration system nor reported to the WHO. Over the last couple of decades, there have been a growing number of studies on suicide and DSH that draw attention to the fact that suicidal behavior is being recognized as a serious public health problem $[11,12]$. However, these are individual level studies that make it difficult to get a national picture of suicidal behavior. The recently published WHO report on suicide estimated that in 2012, there were 13,377 suicides (females 7085; males 6021) in Pakistan, with rates of 7.5 per 100,000 [1]. This is an increase of $2.6 \%$ in rates from the year 2000 [1]. WHO also estimates that for every suicide there are at least 10-20 acts of DSH. By this estimate, there may be between 130,000 to 270,000 acts of DSH in Pakistan annually [1].

Under-reporting and lack of research may occur due to criminalization of suicidal behavior in Pakistan. The Pakistan Penal Code (PPC) 325 states "Whoever attempts to commit suicide and does any act towards the commission of such offence, shall be punished with simple imprisonment for a term which may extend to one year, (or with fine, or with both)". The law itself derives from the tenants of Islam, which strongly condemns suicidal behavior [13]. Under this law every case of suicide or DSH must be taken to one of the city/town's government hospitals that is officially designated as a 'medicolegal center' (MLC). Only the MLCs are authorized to receive cases of suicide and DSH [13]. In reality however, people with DSH avoid going to the MLCs, for fear of legal complications and many seek treatment from private hospitals. Similarly, the latter, in order to protect the individual (and themselves) do not report DSH cases to the police, mislabeling them as either 'accidental' or give them a medical diagnosis. Also, as private medical care in Pakistan is quite expensive, many people leave against medical advice after emergency medical treatment [14]. Therefore, due to both financial reasons as well as legal, socio-cultural and religious stigma surrounding suicidal behavior in Pakistan, the underlying psychosocial issues remain largely unaddressed. The social consequences of suicidal behavior in Pakistan can be quite significant, with families often stigmatized and ostracized [14]. Stigmatization of suicidal behavior in Pakistani society may also be contributing to lack of research on the subject.

Considering the limited evidence available on suicidal behavior in Pakistan, we conducted a scoping review on the subject. The study aims to map the available literature on suicidal behavior in Pakistan, to provide a collective synthesis on the subject, allowing for future research and to inform policy for suicide prevention programs in the country. To the best of our knowledge, no previous study has employed this methodology for mapping suicidal behavior in Pakistan.

\section{Methods}

We conducted a scoping review of suicidal behavior in Pakistan. Scoping review is recommended in settings where there is limited evidence on a subject, as it allows wider coverage of the topic [15].

The following operational definitions were utilized: i) Suicide is defined as an act of self-harm with a fatal outcome [16], ii) Deliberate self-harm (DSH) is defined as a non-fatal act of self-harm carried out with variable motivations [16], iii) Suicidal ideation is defined as thoughts, ideas and desire to commit suicide [17], iv) Determinants are a range of behavioral, biological, socio-economic factors influencing the health of the populations [18] v) Risk factors are characteristics or attributes within an individual that increases the likelihood of a disease [19].

For the review, we followed Arksey and O'Malley's (2005) methodological framework, which includes the following six stages: (i) identification of the research question (ii) identification of relevant studies (iii) study selection (iv) data charting (v) data analysis and reporting the results (vi) consultation exercise [15].

The methods of this scoping review are described in light of the above mentioned six stages.

Stage 1: "What are the risk factors and determinants of suicidal behavior and methods employed in Pakistan?"

Stage 2: We developed a robust search strategy to identify relevant studies on the topic under review. We used a combination of key terms, including "Pakistan" and ("suicide" OR "attempted suicide" OR "parasuicide" 
OR "deliberate self-harm" OR "drug overdose" OR "selfpoisoning" OR "acute poisoning" OR "organophosphate poisoning" OR "suicidal behavior").

We searched ten different electronic databases, from the beginning of their timeframes, including Applied Social Sciences Index and Abstracts (ASSIA), Cochrane Trials Register (CRG), Cumulative Index to Nursing and Allied Health (CINAHL), National Library of Medicine Gateway (NLMG), ExcerptaMedica (EMBASE), National Library of Medicine's MEDLINE (PUBMED), PSYCHINFO, Social Science Citation Index and Science Citation Index (SCI). Pakmedinet.com, a Pakistani medical publication website, was also searched for relevant literature. We also searched 'grey literature' which included unpublished theses and other reports. Databases were searched until December 2016.

The literature search was conducted by the head librarian (KM) who had access to the above databases via Aga Khan University and University of Alberta library resources.

\section{Eligibility criteria}

The inclusion criteria:

- Any study design (primary research, case series or reports)

- Different types of suicidal behavior (including completed suicides, DSH and suicidal ideation)

- Suicidal behavior in both genders and across all ages

- Studies focusing on any of the three aspects: determinants, risk factors or methods employed

The exclusion criteria:

- Studies on Pakistanis residing outside the country (not included because of varied social context)

Variables of interest in each study included sociodemographic details, risk factors and methods employed in the suicidal act.

Stage 3: For study selection, screening was undertaken in two steps. Two reviewers (SS and DH) first screened the abstracts. After application of eligibility criteria, full text of the remaining articles were retrieved, which were also screened by the two reviewers.

Stage 4: The retained articles were entered in a data charting form, developed on Microsoft Excel, based on the literature review and research question. Key attributes of the data charting form included the site of the study, study design, number of subjects and outcome measures, along with specific information on risk factors, determinants and in cases of suicide and DSH, the methods employed. The form was pilot tested and modifications were made accordingly.
Stage 5: Information on distribution and nature of studies was extracted from data charting forms and reported after manual synthesis. The research question consisted of risk factors, determinants and methods employed that formed the basis for analysis. Main characteristics of studies on completed suicides and DSH were also reported in a tabular form. In cases where there was an overlap between risk factors and determinants, it was resolved via mutual consultation within the research team and reported separately.

Stage 6: We also undertook a consultation exercise with the subject expert (MMK) in order to add strength to our study. He also provided additional articles, which were included in the scoping review.

The subject expert also read the results and provided feedback, adding extra value to the review. Badger et al. (2000) recommend utilization of existing knowledge and networks generation of information on primary research [20].

\section{Results}

Through the ten search engines we initially retrieved 623 articles, of which 265 were duplicates and were excluded (Fig. 1). Two reviewers (SS and DS) reviewed the abstracts of the remaining 358 articles individually. In addition, 12 articles were also retrieved from the subject expert. Eighty-two studies not conducted in Pakistan or covering Pakistani population, one poster presentation, four conference proceedings, three articles that could not be retrieved (despite our best efforts) and 162 articles that did not cover suicidal behavior were excluded. One hundred and eighteen articles were read in full, out of which 11 were further excluded (nine were not relevant to our research question, one was a conference abstract and in one, information was difficult to extract), leaving us with 107 articles. To this number, one report and two $\mathrm{PhD}$ dissertations were added, giving a final total of 110 articles included for the final review. Table 1 summarizes the key characteristics of included original studies.

Forty-eight studies were conducted in Sindh (39 from Karachi), 31 in Punjab (16 from Lahore and 11 from Rawalpindi/Islamabad), 9 from KPK (7 from Peshawar) and 2 in Baluchistan. The remaining 20 were describing trends from all over Pakistan.

The reviewed articles consisted of 25 cross-sectional surveys, fourteen prospective case-series and 45 retrospective case series. There were only five case-control studies and only one randomized control trial. 19 articles were literature reviews, commentaries or editorials. One paper was a population-based cohort study.

Rates of suicide or DSH were mentioned in only six studies. Two studies determined rates through descriptive study designs, whereas two from literature review 


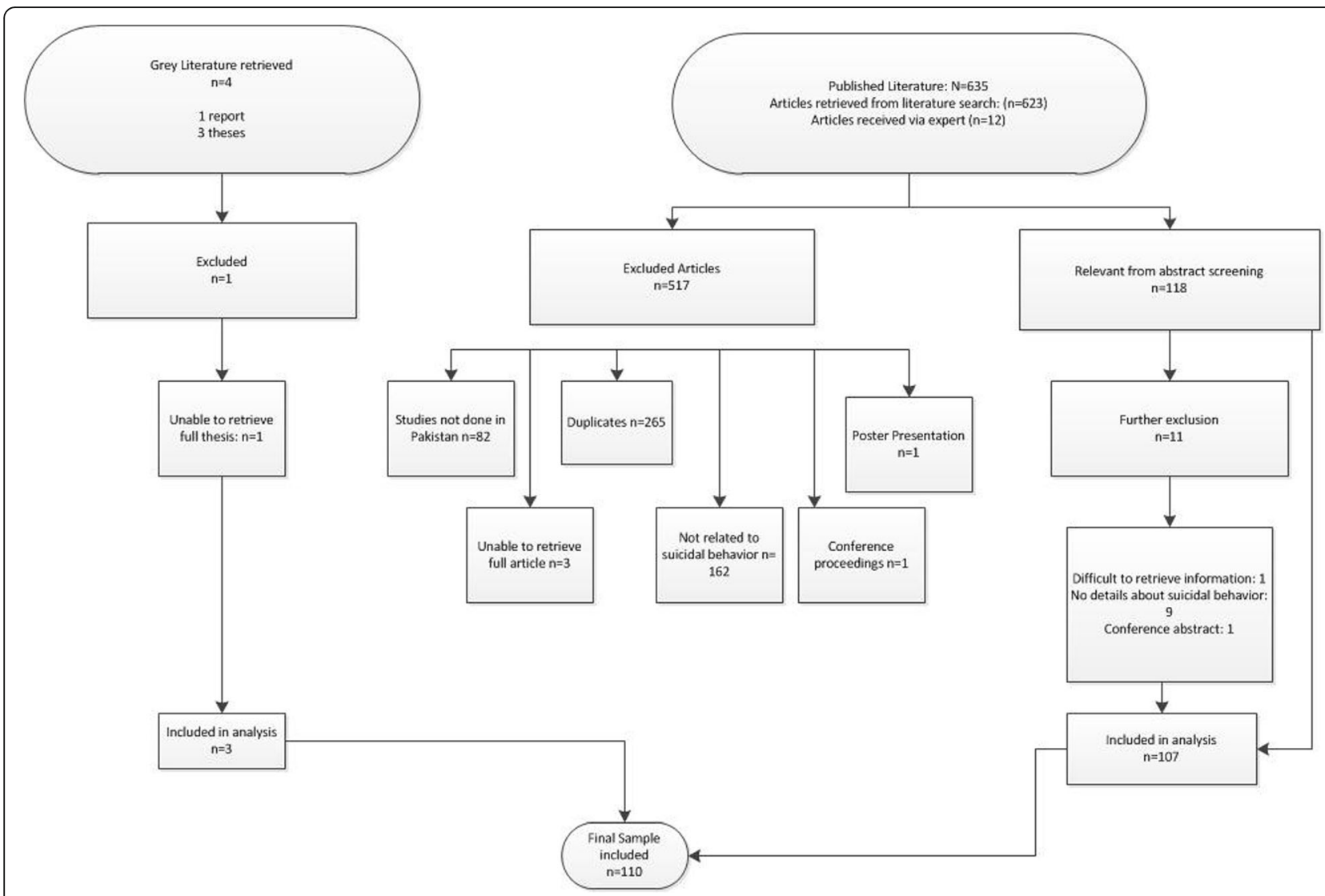

Fig. 1 Consort flow chart

and archival researches. Two studies determined rates of suicides for individual cities [21, 22]. Suicide rates varied from 0.43/100,000/year (for the years 1991-2000) in Peshawar to 2.86/100,000 (in 2006) in Rawalpindi. Gender-specific rates showed lowest and highest rates for men were 0.61/100,000 in Peshawar and 5.2/100,000 in Rawalpindi, respectively and for women $0.23 / 100,000$ in Peshawar and 1.77/100,000 in Larkana, respectively [10, 23]. Average suicide rates for the years 1985-1999 in the province of Sindh was calculated to be 1.15/ 100,000 population $v[10]$.

\section{Determinants}

Gender differences were reported in almost all studies of both completed suicides and DSH. Collectively, more males than females committed suicide. However, 18 studies on DSH reported more females than males, while the trend was reversed in 10 studies. Suicidal ideation was more common in females than males. Data on gender and marital status was not disaggregated in all studies but in studies where disaggregation was done, they showed there are more married than single females in both suicides and DSH [24-26].
A number of studies focused on suicidal behavior in Pakistani women exclusively: six studies on suicidal ideation, three on completed suicides and two on DSH. A study on suicide in women in the Ghizer district in the remote Northern areas of Pakistan showed average annual rates of $14.89 / 100,000$ for the years 2000-2004, with rates in those of over 15 years of age as 33.22/ 100,000 . Important correlates were domestic violence and high levels of psychiatric morbidity [27].

More than half of the studies reported the age of their study sample but used different age ranges. Both suicide and DSH appears to be more common among the young, with majority being less than 30 years of age.

'Unemployment' or 'financial hardship' as a cause of suicidal behavior was also mentioned in a few studies (8 studies on suicide, 8 on DSH and one on suicidal ideation). Unemployment rates varied from $4 \%$ to $39 \%$ in suicides and from $4 \%$ to $86 \%$ for DSH. A case-control study of 100 suicides and matched living controls in Karachi showed that $39 \%$ of cases were unemployed as compared to $17 \%$ of controls [28].

Two studies (one for DSH and one for suicidal ideation) reported on the association between level of income and suicidal behavior. $46 \%-67 \%$ of those who 


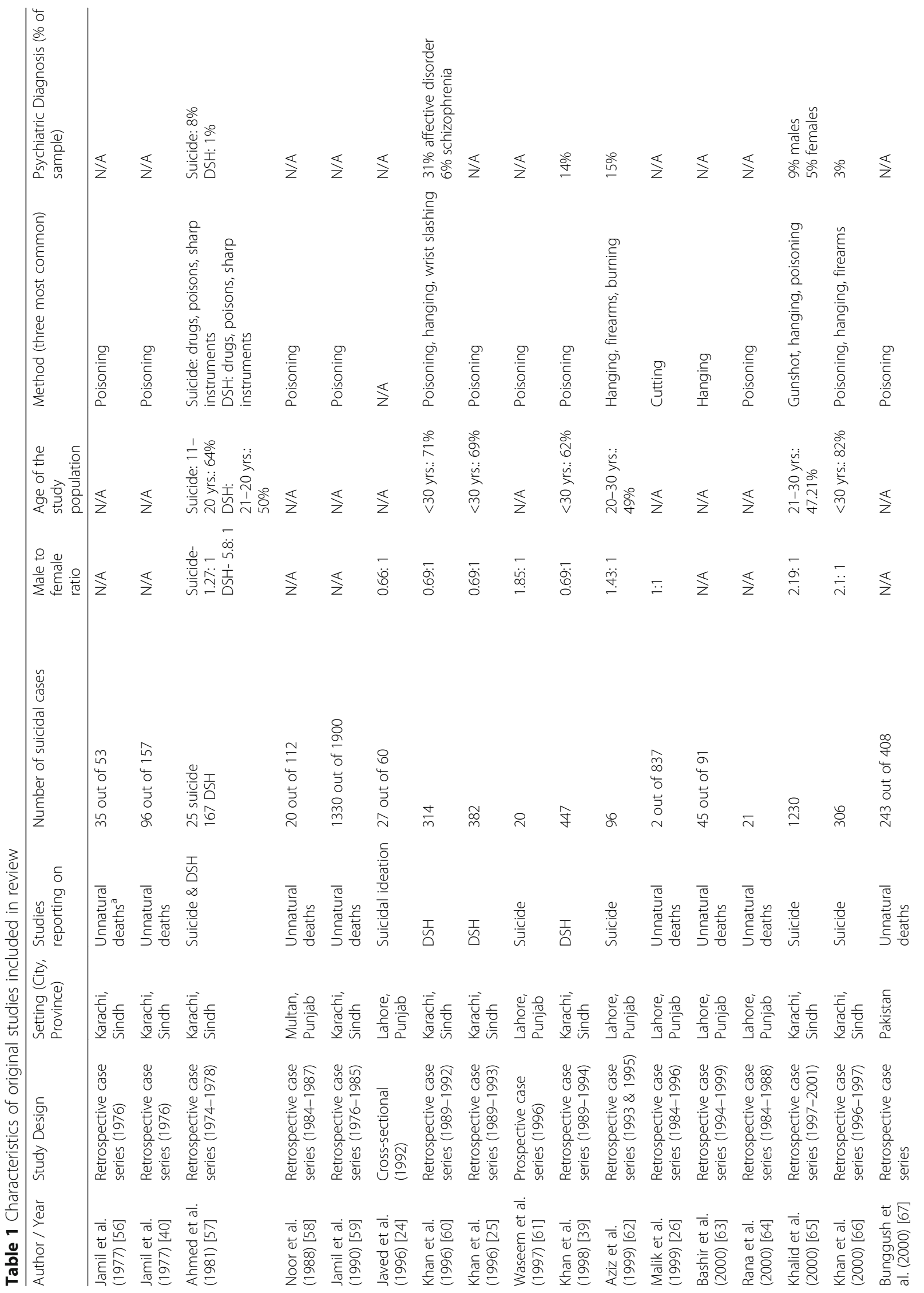




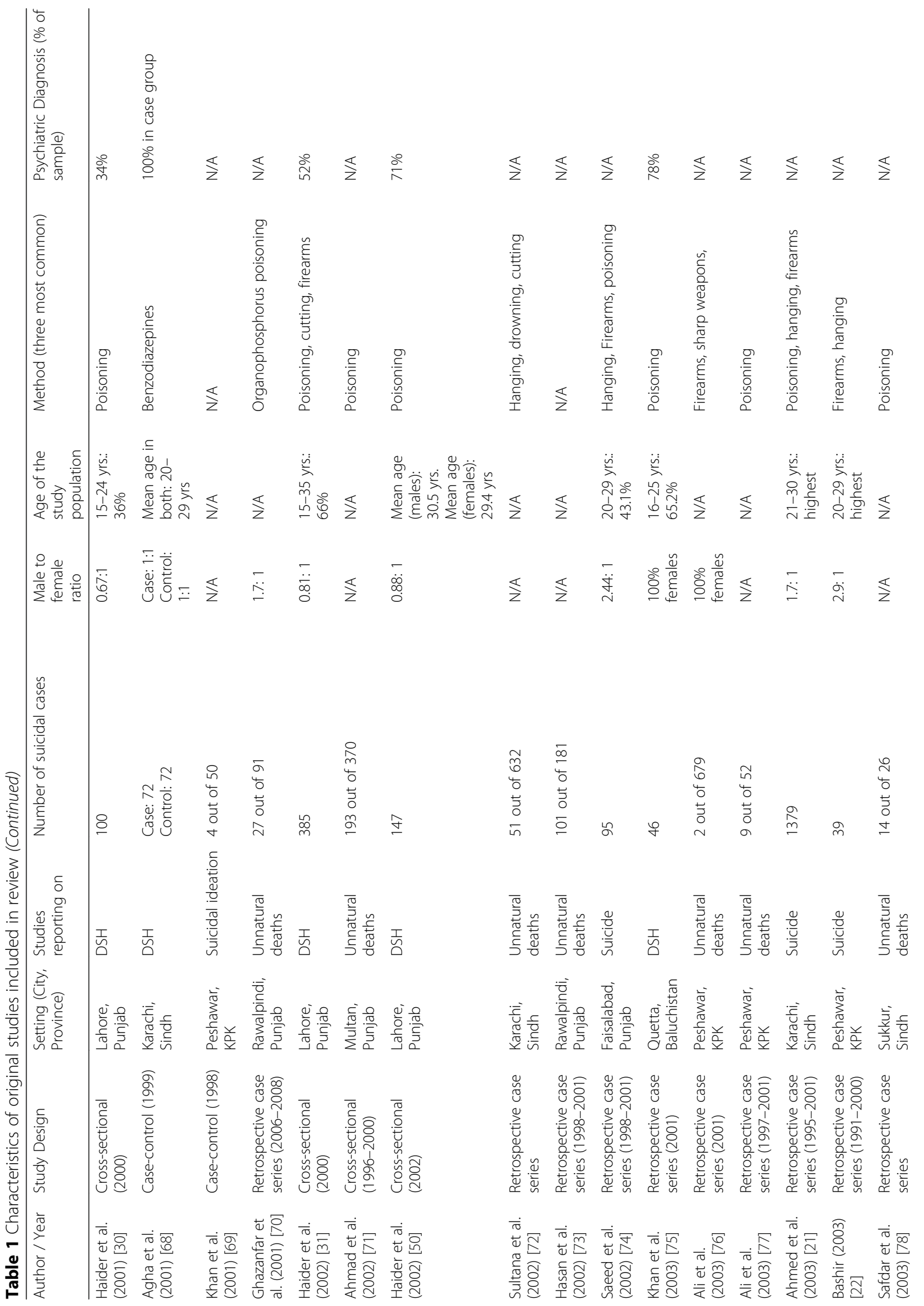




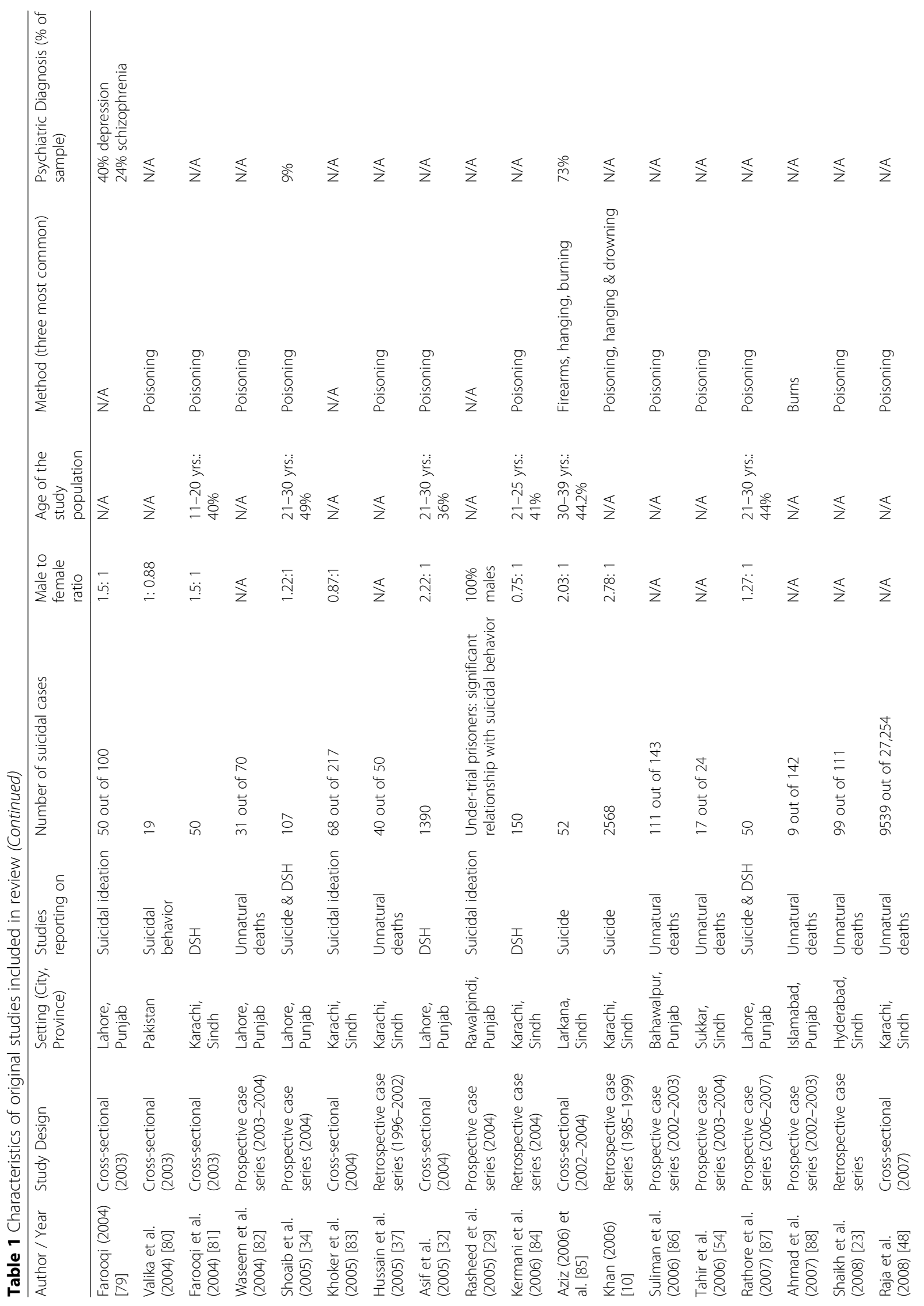




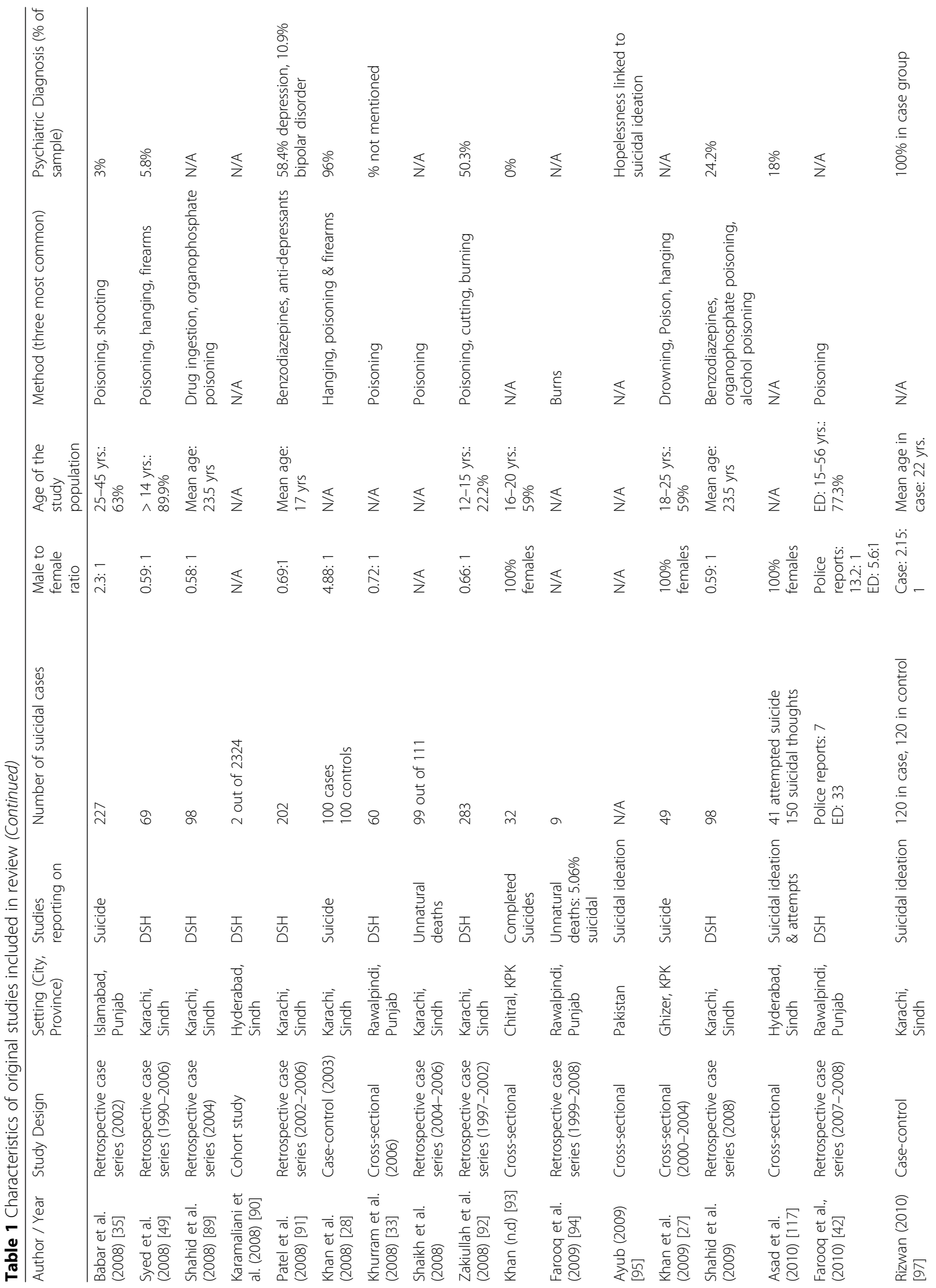




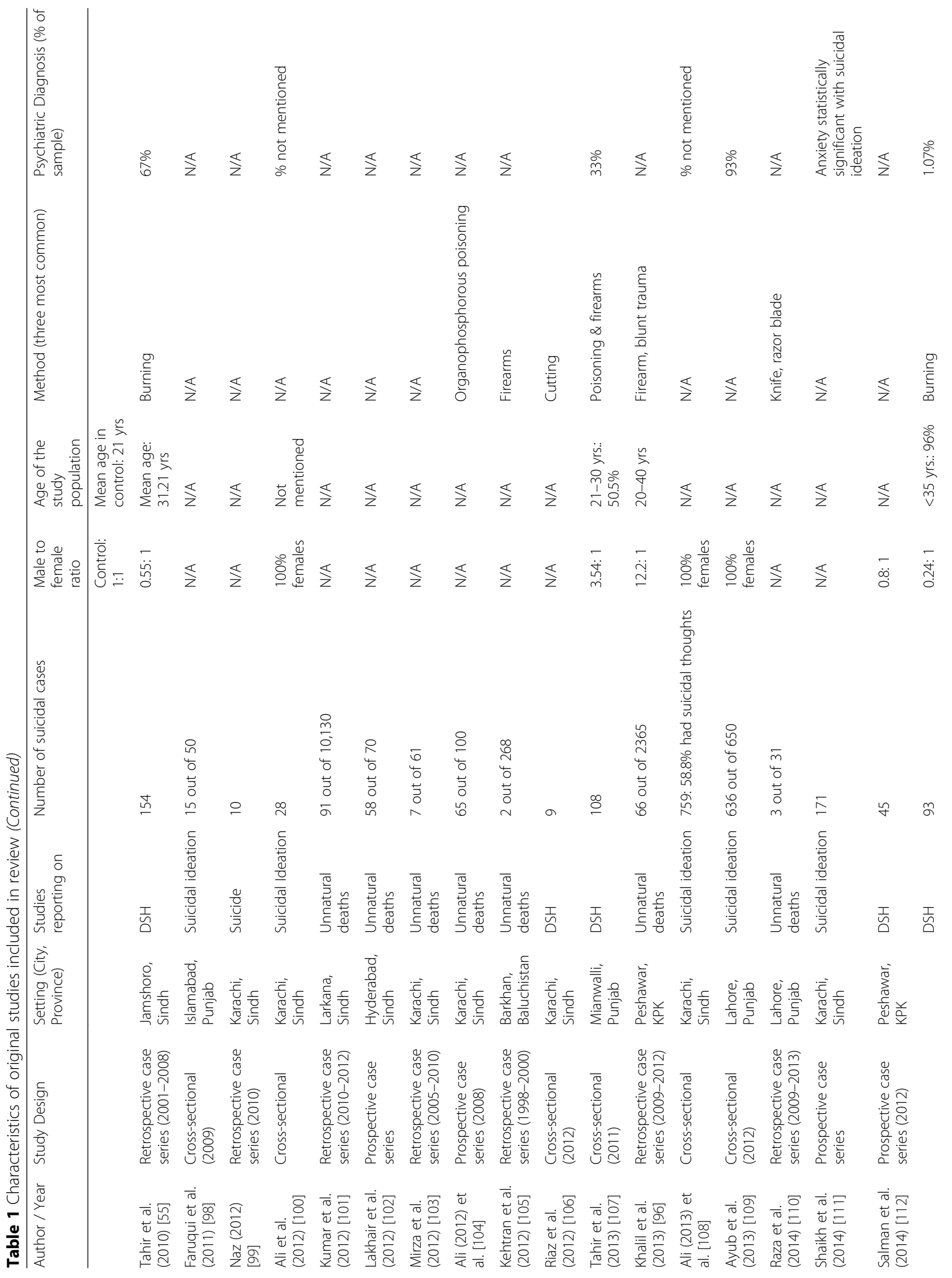




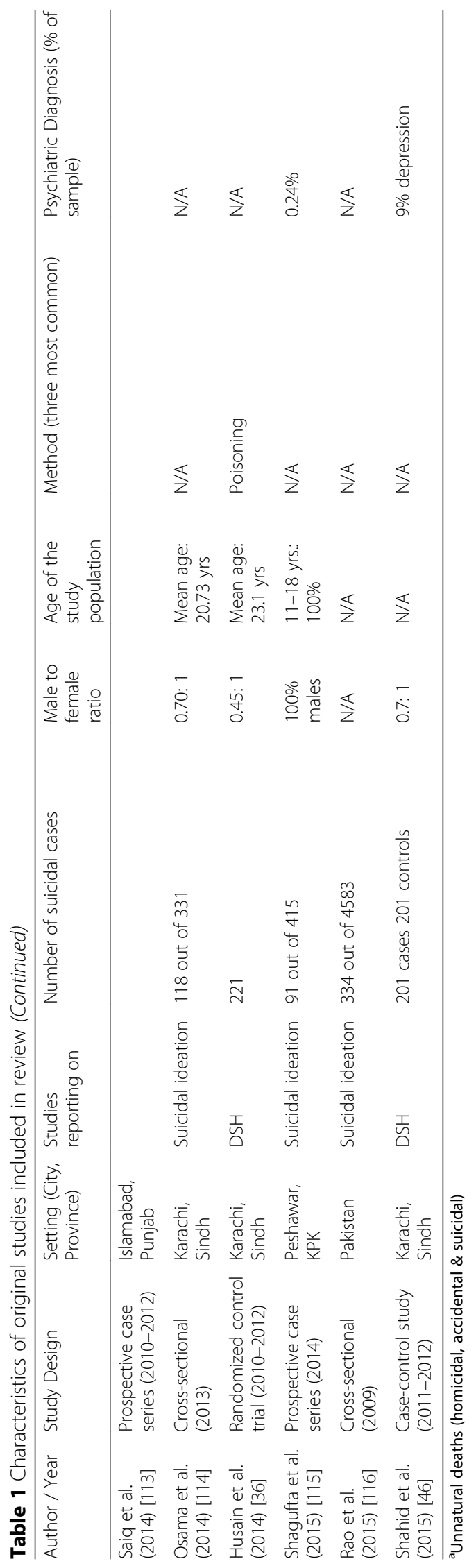


engaged in suicidal behavior had an income of less than Rs. 6000 per month (US \$60) [23, 29]. In four DSH studies, $67 \%$ to $91 \%$ belonged to lower socioeconomic class, whereas only $1 \%$ to $4 \%$ belonged to upper class [30-33].

Level of education was reported in 14 studies: 3 for suicidal ideation, 2 for completed suicides and 9 for DSH and showed that suicidal behavior was more common among those who had little or no education, with rates varying from $30 \%$ to $60 \%$. In the case-control study on suicide, $21 \%$ of cases were uneducated as compared to $4 \%$ of controls [28].

Other determinants that were reported in some studies included occupation. Housewives were $20 \%$ to $60 \%$ while students were $4 \%$ to $17.5 \%$ of the study sample [28, 34, 35].

\section{Risk factors}

While determinants for suicidal behavior were mentioned in several studies (above), only two studies (both were case-control design) investigated risk factors for suicide and DSH specifically. In the DSH study, 'mental illnesses, low socio-economic status and loneliness' were found to the risk factors for patients presenting to three emergency departments of Karachi, while the casecontrol psychological autopsy study of suicide identified six factors: life-events, disrupted social network, level of academic qualification, marital status, ethnicity and depression, that were linked to very high Population Attributable Risk Fractions (PARFs) ranging from 37\% for education to $97 \%$ for life events [28].

There has been only one intervention trial for suicidal behavior in Pakistan, that compared the efficacy of a brief psychological intervention (delivered following an episode of self-harm) with treatment as usual (TAU) [36]. Patients in the intervention group showed statistically significant improvement on the Beck Scale for Suicide Ideation and Beck Hopelessness Inventory, which was sustained at 3 months [36].

\section{Methods for suicidal behavior}

Methods of suicide and DSH were reported in more than $50 \%$ of the studies. The three most common methods for suicide in Pakistan appear to be hanging, ingesting poisons and use of firearms [21, 36-38]. Amongst 'poisons', the majority of victims used insecticides and pesticides, (that contain organophosphate (OP) compounds), that are available in most homes in the urban areas and used in agriculture in the rural areas of Pakistan respectively. Despite being freely available over-the-counter, medications (including analgesics and psychotropics) are not used widely as means to commit suicide. In contrast, self-poisoning with medications (particularly benzodiazepines) was the most common method in DSH in the urban areas [39]. On the other hand, self-poisoning was more common in both suicide and DSH in semi-urban or rural areas [40].

\section{Discussion}

This scoping review is the first attempt to synthesize the available literature on suicidal behavior in Pakistan. The results reveal that there are significant gaps in evidence.

Majority of the studies are from the main urban centers of the country, and there is dearth of data from rural areas, despite the fact that almost two-thirds of the population in Pakistan lives in rural areas.

Most of the studies reviewed were descriptive in nature (majority were case series and cross-sectional surveys that do not allow for the establishment of relationships), with only five case-control studies.

A number of studies were on "unnatural deaths", in which the manner of death (for example, whether accidental, homicidal or suicidal) was not disaggregated, making it difficult to study the characteristics (such as age, gender or marital status) of the suicidal group separately.

Lack of official statistics for suicide prevents the problem being recognized. Since suicide and DSH remain criminal acts in Pakistan, this further poses a challenge in accurate data collection [41]. Studies have reported a discrepancy in reported rates between newspaper reports and police data [42]. In Pakistan, given the strong religious views against suicide, decriminalization may be perceived as endorsing suicidal behavior as a way out of one's problems [43]. However, as the WHO estimates show (an increase of $2.6 \%$ in suicide rates between 2000 and 2012) religion may not be as strong a deterrent as previously perceived [1]. Decriminalization would have the effect of partly decreasing the stigma surrounding the act, thus allowing people to seek help without fear of prosecution or harassment by the law enforcement authorities. Although the Mental Health Act of 2001 has made some provisions for the protection of those who attempt suicide by including that "a person who attempts suicide shall be assessed by an approved psychiatrist and if found to be suffering from a mental disorder shall be treated appropriately under the provisions of this Ordinance", this has yet to translate into practice. More recently, there is some indication that suicidal behavior may be decriminalized in Pakistan [44]. Indeed if this was to happen, it would be a major step in eliminating the stigma and addressing the psychological needs of suicidal persons in the country.

Despite the poor quality of many studies one consistent finding that emerges in our review is that gender is an important determinant for suicide and DSH in Pakistan, especially when considered in the context of marital status. There was a larger representation of married women 
compared to single women or married or single men. It appears that unlike the West, where it is protective, marriage is a risk factor for psychiatric morbidity and suicidal behavior for Pakistani women [45]. Associated factors include early age of marriage, lack of autonomy in choice of male partner ('arranged marriage'), pressure to have children early in the marriage, desire for a male offspring, curtailment of education, economic dependence on husband, joint or extended family system and domestic violence [46]. These factors put many young married women in Pakistan in a highly disadvantaged position and many resort to suicidal behavior as a way to express their distress. Other studies report that being a female in Pakistan is in itself a risk factor for suicide and DSH, with lack of employment being a significant determinant, and its association with issues of control and empowerment [47].

This scoping review shows that majority of individuals who engaged in suicidal behavior are below the age of 30 years, underscoring the need to address mental health and other issues faced by young people in Pakistan. Conversely, suicide and DSH was uncommon among the elderly, a finding that is in sharp contrast to studies from the West [48]. Part of the explanation may lie in the fact that in Pakistan, few elderly people are socially isolated or live on their own where they have to fend for themselves. The majority are looked after by their families, who provide both physical as well as financial support.

Unemployment and financial hardships appear to be strongly correlated with both suicide and DSH, particularly among males in Pakistan [49]. Unemployment, poor economic conditions and rising poverty are macro level factors in suicidal behaviors that need to be addressed at policy levels [50].

Low educational attainment strongly correlated with both suicide and DSH in the studies we reviewed. This is likely mediated through poor stress coping abilities, inability to compete for jobs or acquire greater social standing [51].

Our scoping review showed that poisoning is the second most common method (after hanging) in suicides in Pakistan. Amongst poisons, organophosphorous compounds feature highly in both DSH and suicide. These substances are highly toxic due to their anticholinesterase effects, leading to a high case-fatality index (even in cases with low suicidal intent). The free availability of pesticides in rural areas pose particular risk to those working in the agriculture sector in Pakistan, shown by their increased use in cases of self-poisoning. This is compounded by the absence of quality medical care in cases of poisonings in Pakistan.

As part of its suicide prevention strategy, the WHO lists restricting access to toxic agents as one of its recommendations. Trials of 'locked boxes' (that restrict access to toxic pesticides in crisis situations) undertaken in India and Sri Lanka have given encouraging results [52]. WHO also recommends use of less toxic pesticides for agricultural purposes, i.e. Class I OP pesticides and Class II endosulfan [52]. Both these measures could be applied for suicide prevention in Pakistan.

The increased use of firearms in suicides in Pakistan reflects their growing availability in the country, estimated at more than 20 million (of which only 7 million are registered), with almost 13,000 annual homicides [53]. There is urgent need for firearm control in the country.

This paper highlights the lack of studies on risk factors for suicide and DSH in Pakistan. Mental illness as a risk factor is addressed in a small minority of studies reviewed. This may be due to the fact that most studies in our review were conducted by non-mental health professionals $[33,54,55]$, who are not sensitized to study mental illness in suicidal behaviors. Data is also biased away from mental illness as a risk factor due to stigma surrounding mental illness and suicidal behavior in itself.

There are serious lacunae and weaknesses in the current system of registration and diagnosing of suicidal behavior in Pakistan. There is lack of standardized system of certifying suicidal deaths across the country. Processes to investigate suicides are weak and influenced by socio-political and cultural factors. For example due to stigma it is not uncommon for families to have the suicidal death registered as an accident or a medical condition [2]. Conversely, many cases of homicide (particularly where the woman is set on fire by the husband and/or in-laws) are labeled as self- immolation suicides. Therefore, there is underreporting of suicidal behaviors in the country, the true extent of which is difficult to determine.

Currently, data on suicide and DSH is neither included in the National Health Morbidity Statistics nor reported to the WHO. As a consequence national rates of suicide are not known [1]. On the other hand, as several healthfacility based studies in our review show, cases of DSH do report to health facilities across the country. With decriminalization and a proper system for recording and collating data, it is possible to get a better picture of the problem in the country.

\section{Recommendations}

There is an urgent need for DSH and suicide mortality statistics to be collected through a standard system of registration, recording and diagnosis, at all town/city, district and provincial levels throughout the country. The information obtained can be used for epidemiologicalanalytical, intra-country and cross-national studies. A mandatory reporting of suicide mortality statistics to the 
WHO would help improve data collection and surveillance of suicides and DSH in Pakistan.

Based on this review's findings, there emerges a need for improving the system of investigating and diagnosing suicides in the country. Training and education of key personnel involved in the process is vital, including the police, medico-legal officers, forensic medical specialists as well as general/family physicians.

Prohibiting use of the more toxic pesticides and replacing them with less toxic ones can help prevent many suicidal deaths, especially those with a low suicidal intent. There is need for improved emergency medical treatment for DSH victims, particularly those of selfpoisoning with toxic agents.

This scoping review signifies that the existing evidence on suicidal behavior is limited in the context of Pakistan. Therefore, more robust analytical research designs such as case control and psychological autopsy methods are needed with a focus on risk factors, particularly mental illness. There is also need for intervention studies for prevention of suicidal behaviors in Pakistan.

All of the above recommendations demonstrate the need to have suicide prevention programs with an integrated research agenda in the existing health systems of Pakistan.

\section{Acknowledgements}

We gratefully acknowledge the assistance of Ms. Linda Slater of John W Scott Health Sciences Library at University of Alberta, Canada.

\section{Funding}

The Small Grant program of Department of Emergency Medicine, Aga Khan University and Fogarty John Hopkins University-Pakistan, International Collaborative Trauma and Injury Research Training (ICTIRT) Program.

\section{Availability of data and materials}

All articles cited in text are available online.

\section{Authors' contributions}

SS was one of the independent reviewers responsible for screening the articles for relevance, who also took part in analysis of data and writing the manuscript. SP envisaged the idea of a scoping review for suicidal behavior in Pakistan, took part in analysis of data, guided the methodological write up of manuscript and reviewed multiple drafts. DH reviewed the articles for relevance and helped in writing the manuscript. KA devised the search strategy and conducted the search. SB facilitated in conducting the search. MMK was the lead expert of the team, who analyzed the data and wrote part of the manuscript. All authors read and approved the final manuscript.

\section{Ethics approval and consent to participate}

Ethical approval has been granted by the Ethics Review Committee (ERC) of Aga Khan University.

\section{Consent for publication}

Not applicable.

\section{Competing interests}

The authors declare that they have no competing interests.

\section{Publisher's Note}

Springer Nature remains neutral with regard to jurisdictional claims in published maps and institutional affiliations.

\section{Author details}

${ }^{1}$ Department of Psychiatry, Aga Khan University, Karachi, Pakistan.

2Department of Community Health Sciences, Aga Khan University, Karachi, Pakistan. ${ }^{3}$ Aga Khan University, Karachi, Pakistan. ${ }^{4}$ Drexel University College of Medicine/Hahnemann University Hospital, Philadelphia, PA, USA.

Received: 19 June 2017 Accepted: 29 December 2017

Published online: 12 February 2018

\section{References}

1. World Health Organization. Preventing suicide: a global imperative. World Health Organization, 2014. http://apps.who.int/iris/bitstream/10665/131056/ 8/9789241564878_eng.pdf?ua=1\&ua=1. Accessed 15 Jan 2017.

2. Khan MM, Reza H. Gender differences in non-fatal suicidal behavior in Pakistan: significance of sociocultural factors. Suicide Life Threat Behav. 1998;28:62-8.

3. Amitai $M$, Apter $A$. Social aspects of suicidal behavior and prevention in early life: a review. Int J Environ Res Public Health. 2012;9:985-94.

4. Jacob K. The prevention of suicide in India and the developing world: the need for population-based strategies. Crisis. 2008;29:102-6.

5. Jordans MJ, Kaufman A, Brenman NF, Adhikari RP, Luitel NP, Tol WA, et al. Suicide in South Asia: a scoping review. BMC Psychiatry. 2014;14:1.

6. Mahar A. Pakistan's youth bulge: human resource development (HRD) challenges. 2014. http://www.ipripak.org/pakistans-youth-bulge-humanresource-development-hrd-challenges/\#sthash.QKwW71 n0.2IJOalJD.dpbs. Accessed 15 Jan 2017.

7. World Bank. World Bank: Total population 2014. http://data.worldbank.org/ indicator/SP.POP.TOTL. Accessed 15 Jan 2017

8. Kiani K. Pakistan ranks low in social indicators dawn; 2007. http://www. dawn.com/news/274427/pakistan-ranks-low-in-social-indicators. Accessed 15 Jan 2017.

9. Mirza I, Jenkins R. Risk factors, prevalence, and treatment of anxiety and depressive disorders in Pakistan: systematic review. BMJ. 2004;328:794.

10. Khan MM, Ali Hyder A. Suicides in the developing world: case study from Pakistan. Suicide Life Threat Behav. 2006:36:76-81.

11. Khattak I. Poverty drove 52 to suicide last year. Dawn; 2007. http://www. dawn.com/news/228465/poverty-drove-52-to-suicide-last-year. Accessed 15 Jan 2017.

12. Ebrahim ZT. The alarming rise of teenage suicides in Pakistan. Dawn; 2012. http://www.dawn.com/news/724902. Accessed 15 Jan 2017.

13. Mahmood S. The Pakistan penal code (XLV of 1880), vol. II, sections $300-$ 374. Legal Research Centre: Lahore; 1989.

14. Shahid M, Khan MM, Saleem Khan M, Jamal Y, Badshah A, Rehmani R. Deliberate self-harm in the emergency department: experience from Karachi, Pakistan. Crisis. 2009;30:85-9.

15. Arksey H, O'Malley L. Scoping studies: towards a methodological framework. Intl J Soc Res Methodol. 2005;8:19-32.

16. Soomro GM. Deliberate self-harm (and attempted suicide). BMJ clinical evidence. 2008;

17. Silva RJ, Santos FA, Soares NM, Pardono E. Suicidal ideation and associated factors among adolescents in Northeastern Brazil. Sci. World J. 2014;

18. World Health Organization. The World health report. Changing history. 2004 http://wwwwhoint/whr/2004/en/report04_enpdf Accessed. 2004;(15 Jan 201)

19. World Health Organization. Risk factors. http://www.who.int/topics/risk_ factors/en/

20. Badger D, Nursten J, Williams P, Woodward M. Should all literature reviews be systematic? IJRE. 2000;14:220-30.

21. Ahmed Z, Ahmed A, Mubeen SM. An audit of suicide in Karachi from 1995-2001. Ann Abbasi Shaheed Hosp. 2003:8:424-8.

22. Bashir MZ. Suicidal deaths: assessment in Peshawar. The Professional. 2003;

23. Shaikh JM, Siddiqui FG, Soomro AG. Management of acute organophosphorus insecticide poisoning: an experience at a university hospital. JLUMHS. 2008;7:96-101.

24. Javed MA. Suicidal symptoms in depressed Pakistani patients. J Pak Med Assoc. 1996;46:69-70.

25. Khan MM, Reza H. Methods of deliberate self-harm in Pakistan. The Psychiatrist Bulletin. 1996. Jun 1;20:367-8.

26. Malik S, Rana P, Rasheed A, Farrukh R, Aziz K. Self-inflicted or homicidal cut throat: a retrospective study. Ann King Edward Med Uni. 1999;5:325. 
27. Khan MM, Ahmed A, Khan SR. Female suicide rates in Ghizer, Pakistan. Suicide Life-Threat Behav. 2009;39:227-30.

28. Khan MM, Mahmud S, Karim MS, Zaman M, Prince M. Case-control study of suicide in Karachi, Pakistan. Br J Psychiatry. 2008;193:402-5.

29. Rasheed S, Sawal M, Taj R, Najam N. Relationship between suicidal ideation, social support and coping skills in female prisoners of a jail in Pakistan. J Pak Psych Soc (JPPS). 2005;2

30. Haider S, Haider I. Deliberate self-harm. J Pak Med Sci. 2001;17:1-7.

31. Haider S, Haider I. Suicidal Behavior (Parasuicide). Med Channel. 2002;8:9-12

32. Asif A, Yusuf F, Haider K, Gul H, Usman S, Akbar S, et al. Epidemiology of attempted suicides in emergency of Mayo Hospital in 2004. Ann King Ed Med Uni. 2016;11

33. Khurram M, Mahmood N. Short communication-deliberate self-poisoning: experience at a medical unit. J Pak Med Assoc. 2008:58:455

34. Shoaib S, Nadeem MA, Khan ZU. Causes and outcome of suicidal cases presented to a medical ward. Ann King Ed Medic Uni. 2016.7;11(1).

35. Babar M, Qazilbash AA. Factors associated with increased suicides among Pakistani youth: A case study of 366 attempted suicides in Sindh.

36. Husain N, Afsar S, Ara J, Fayyaz H, Ur Rahman R, Tomenson B, Hamirani M, Chaudhry N, Fatima B, Husain M, Naeem F. Brief psychological intervention after self-harm: randomised controlled trial from Pakistan. Br J Psychitary. 2014;204:462-70

37. Hussain AM, Sultan ST. Organophosphorus insecticide poisoning: management in surgical intensive care unit. JCPSP. 2005;15:100-2.

38. Shahid M, Hyder AA. Deliberate self-harm and suicide: a review from Pakistan. Int J Inj Control Saf Promot. 2008;15:233-41.

39. Khan MM, Reza H. Benzodiazepine self-poisoning in Pakistan: implications for prevention and harm reduction. J Pak Med Assoc. 1998;48:293-5.

40. Jamil H, Khan A, Akhtar S, Sultana N. Patients with acute poisoning seen in the department of intensive care-Jinnah postgraduate medical Centre, Karachi. J Pak Med Assoc. 1977;27:358-60.

41. Kahn DL, Lester D. Efforts to decriminalize suicide in Ghana, India and Singapore. Suicidology Online. 2013;4:96-104.

42. Farooq U, Majeed M, Bhatti JA, Khan JS, Razzak JA, Khan MM. Differences in reporting of violence and deliberate self harm related injuries to health and police authorities, Rawalpindi, Pakistan. PLoS One. 2010;5:e9373.

43. McLean J, Platt S, Harris F, Repson R. Risk and protective factors for suicide and suicidal behaviour: a literature review. 2008.

44. Hussain D. Attempted suicide to be decriminalized. The Express Tribune. 2017; Retrieved from: https://tribune.com.pk/story/1518119/attemptedsuicide-decriminalised/

45. Shah A, De T. Suicide and the elderly. Intl J Psych Clinical Pract. 1998;2:3-17.

46. Shahid M, lqbal R, Khan MM, Khan MZ, Shamsi US, Nakeer R. Risk factors for deliberate self-harm in patients presenting to the emergency Departments of Karachi. J Coll Physicians Surg Pak. 2015;25:50.

47. Qadir F, Khan MM, Medhin G, Prince M. Male gender preference, female gender disadvantage as risk factors for psychological morbidity in Pakistani women of childbearing age-a life course perspective. BMC Pub Health. 2011;11:1.

48. Raja KS, Fazal MO, Bilal A, Qurashi FS, Shaheen M. Organophosphorus compound poisoning; epidemiology and management (atropinization vs pralidoxime) a descriptive analysis, in allied hospital Faisalab. Professional Med J. 2008;15:518-23.

49. Syed EU, Khan MM. Pattern of deliberate self-harm in young people in Karachi, Pakistan. Crisis. 2008:29:159-63.

50. Haider S, Haider I. Deliberate self-poisoning (unemployment and debt). J Pak Med Sci. 2002;18:122-5.

51. Sathar ZA, Kazi S, Mahmood A. Pakistani couples: different productive and reproductive realities. The Pakistan Development Review. 2000:891-912.

52. Pearson M, Konradsen F, Gunnell D, Dawson AH, Pieris R, Weerasinghe M, Knipe DW, Jayamanne S, Metcalfe C, Hawton K, Wickramasinghe ARA. Community-based cluster randomised trial of safe storage to reduce pesticide self-poisoning in rural Sri Lanka: study protocol. BMC Public Health. 2011;11:879.

53. Zia-ur-Rehman. Smoking Guns. The Friday Times; 2012. http://www. thefridaytimes.com/beta3/tft/article.php?issue=20121130\&page $=4$

54. Tahir M, Raja J, Haq I. Acute Organophosphorous poisoning-an experience. PAMFJ. 2006:56

55. Tahir SM, Memon AR, Kumar M, Ali SA. Self inflicted burn; a high tide. J Pak Med Associ. 2010;60:338.

56. Jamil H, Kundi A, Akhtar S, Sultana N. Organo-phosphorus insecticide poisoning-review of 53 cases. J Pak Med Assoc. 1977;27:361-3.
57. Ahmed $\mathrm{SH}$, Zuberi $\mathrm{H}$. Changing pattern of suicide and parasuicide in Karachi. J Pak Med Assoc. 1981;31:76-8.

58. Noor NA, Qazi NA, Chaudhry GM, Masood M, Hashmat MA, Asif AH. Acute poisoning in adults in Multan. JPMA. J Pak Med Assoc. 1988;38:305-6.

59. Jamil H. Acute poisoning: a review of 1900 cases. J Pak Med Assoc. 1990;40: $131-3$.

60. Khan MM, Islam S, Kundi A. Parasuicide in Pakistan: experience at a university hospital. Acta Psychiat Scan. 1996;93:264-7.

61. Waseem T, Raza T, Nasir N, Khan A. Myocardial damage after suicidal ingestion of wheat preservative Aluminium phosphide. PJC. 1997;8:43-8.

62. Aziz K, Awan NR. Pattern of suicide and its relationship to socio-economic factors/depressive illness in the city of Lahore. Specialist Quarterly karachi. 1999:15:289-94.

63. Bashir MZ, Malik AR, Malik SA, Rana PA, Aziz K, Chaudhry MK. Pattern of fatal compression of the neck. A five year study in Lahore. Annals. 2000;6:396-8.

64. Rana PA, Farrukh R, Malik SA, Rasheed A. Incidence of fatal poisoning in the city of Lahore: a retrospective study during 1984-88 Lahore. Ann KE Med Coll. 2000;6:112-5.

65. Khalid N. Pattern of suicide: causes and methods employed. JCPSP. 2001;11: 759-61.

66. Khan MM, Reza H. The pattern of suicide in Pakistan. Crisis. 2000;21:31.

67. Bunggush RA, Anwar T. Preliminary survey for pesticide poisoning in Pakistan. Pak J Biol Sci. 2000;3:1976-8.

68. Agha, S. Suicidal behavior as a function of psychosocial risk factors in Pakistan. 2001

69. Khan MZ, Naeem A, Mufti KA. Prevalence of mental health problems in acne patients. J Ayub Med Coll Abbottabad. 2001;13:7.

70. Ghazanfar S, Leghari A, Qureshi S, Niaz SK, Quraishy MS. Corrosive esophageal strictures: behavior, pattern and response to dilatation. J Gastroenterol Hepatol. 2010;1(25):A129-30.

71. Ahmad R, Ahad K, labal R. Acute poisoning due to commercial pesticides in Multan. Pak J Med Sci. 2002;18:227-31.

72. Sultana K. Proportion of suicidal deaths among autopsy. Ann Abbasi Shaheed Hosp. 2002;7:317-8.

73. Hasan Z, Rehman A, Khurram M, Shah W. Self-inflicted injuries: the standing medical board experience. JCPSP. 2002:12:18-21.

74. Saeed A, Bashir MZ, Khan D, Iqbal J, Raja KS, Rehman A. Epidemiology of suicide in Faisalabad. J Ayub Med Coll Abbottabad. 2002;14:34-7.

75. Muhammad NK, Shamim H. Deliberate self harm due to organophosphates. JPIMS. 2003;14:784-9.

76. Ali SM, Bashir MZ, Hussain Z, Kaheri GQ, Khalil IU. Unnatural female deaths in Peshawar. JCPSP. 2003;13:198-200.

77. Ali SM, Khalil IU, Saeed A, Hussain Z. Five years audit for presence of toxic agents/drug of abuse at autopsy. JCPSP. 2003;13(9):519-21.

78. Safdar A, Saeed A, Muhammad NR. Organophosphorus poisoning: emergency management in intensive care unit. Prof. 2003;10:308-14.

79. Farooqi YN. Comparative study of suicide potential among Pakistani and American psychiatric patients. Death studies. 2004 Jan 1;28:19-46.

80. Valika R, Jalbani AA. Suicide Trends: Incidences from Pakistan. JISR. 2004;2:44

81. Farooqi AN, Tariq S, Asad F, Abid F, Tariq O. Epidemiological profile of suicidal poisoning at Abbasi Shaheed hospital. Ann Abbasi Shaheed Hosp Med \& Dental Coll. 2004;9:502-5

82. Waseem T, Nadeem MA, Irfan K, Waheed I. Poisonings in patients of medical coma and their outcome at Mayo Hospital Lahore. Ann King Edward Med Uni. 2016 May;16:10(4).

83. Khokher S, Khan MM. Suicidal ideation in Pakistani college students. Crisis. 2005;26:125-7.

84. Kermani F, Ather NA, Ara J. Deliberate self harm: frequency and associated factors. J surg Pak. 2006;11:34-6.

85. Aziz K, Afridi HK, Khichi ZH. Psychological autopsy study of suicide pattern and its relationship to depressive illness. Ann King Ed Med Uni. 2006;12

86. Suliman Ml, Jibran R, Rai M. The analysis of organophosphates poisoning cases treated at Bahawal Victoria hospital, Bahawalpur in 2000-2003. Pak J Med Sci. 2006:22:244-9.

87. Rathore R, Muhammad U. Morbidity, mortality and Management of Wheat Pill Poisoning. J services Inst Med Sci. 2007:2:14-8.

88. Ahmad M, Hussain SS, Khan MI, Malik SA. Experience of burn injuries at the Pakistan institute of medical science, Islamabad, Pakistan. Annals of burns and fire Disasters. 2007;20:7.

89. Shahid M, Khan MM, Naqvi H, Razzak J. Cost of treatment of deliberate selfharm: a study from Pakistan. Crisis. 2008 Jul;29:213-5. 
90. Karmaliani R, Irfan F, Bann CM, Mcclure EM, Moss N, Pasha O, Goldenberg RL. Domestic violence prior to and during pregnancy among Pakistani women. Acta Obstet Gynecol Scand. 2008;87:1194-201.

91. Patel MJ, Shahid M, Riaz M, Kashif W, Ayaz SI, Khan MS, Samdani AJ, Sorathia AL, Furqan M. Drug overdose: a wake up call! Experience at a tertiary care centre in Karachi, Pakistan. J Pak Med Assoc. 2008;58:298.

92. Zakiullah N, Saleem S, Sadiq S, Sani N, Shahpurwala M, Shamim A, Yousuf A, Khan MM, Nayani P. Deliberate self-harm: characteristics of patients presenting to a tertiary care hospital in Karachi, Pakistan. Crisis. 2008;29:32-7

93. Khan, Z. Causes of high rate of suicide among women in Chitral. n.d.

94. Farooq IA, Afzal W, Salman M. Medicolegal aspect of burn victims: a ten years study. Pak J Med Sci. 2009;25(5):797-800

95. Ayub N. Measuring hopelessness and life orientation in Pakistani adolescents. Crisis. 2009;30:153-60.

96. Khalil ZH, Naeem M, Adil M, Khan MZ, Abbas SH. Analysis of autopsy record of unnatural deaths in Peshawar district. J Postgrad Med Inst. 2013;27

97. Rizwan, M. Self-esteem deficits and suicidal tendencies among psychiatric patients. 2010

98. Faruqui R, Bashir A, Taj A, Khan A, Yousaf F, Waheed F, Ayub Z, Bibi A. Prevalence of suicidal ideation and desire for death in a group of female muslim students one year after exposure to suicide bomb attack in Pakistan. Eur Psychiatry. 2011;26:1663.

99. Naz R. Lethality of suicidal Organophosphorous poisoning in Karachi in 2010. Medical Forum. 2012

100. Ali TS, Krantz G, Mogren I. Violence permeating daily life: a qualitative study investigating perspectives on violence among women in Karachi, Pakistan. Int J Womens Health. 2012;4:577.

101. Kumar K, Chand H, Shaikh SA. Spectrum of Medicolegal Cases in Physical Injury at Chandka Medical College, Larkana, Pakistan. Thorax. 487:4-81.

102. Lakhair AL, Shaikh MA, Kumar S, Zafarullah, Bano R, Maheshwari BK. Frequency of Various Clinical and Electrocardiac Manifestation in Patients with Acute Organophosphorous Compound (OPC) Poisoning. JLUMHS. 2012;11:34.

103. Mirza FH, Memon AA, Adil SE, Paryar HA. Audit of custodial deaths in Karachi-an autopsy-based study. J Pak Med Assoc. 2012;62:752.

104. Ali P, Anwer A, Bashir B, Jabeen R, Haroon H, Makki K. Clinical pattern and outcome of organophosphorus poisoning. J Liaq Uni Med Health Sci. 2012;11:15-8.

105. Khetran AK, Rehman S, Khan Z, Baloch MU. Incidence of deaths due to gunshot injuries at district Barkhan, Balochistan. JLUMHS. 2012;11:90.

106. Riaz R, Agha S. Efficacy of cognitive behavior therapy with deliberate selfharm in incarcerated women. Pak J Psychol. 2012;27:21.

107. Tahir MN, Akbar AH, Naseer R, Khan QO, Khan F, Yaqub I. Suicide and attempted suicide trends in Mianwali, Pakistan: social perspective/ Tendances des suicides et des tentatives de suicide à Mianwali (Pakistan)^ sup o^: perspective sociale. East Mediterr Health J. 2013;19:S111.

108. Ali TS, Mogren I, Krantz G. Intimate partner violence and mental health effects: a population-based study among married women in Karachi, Pakistan. Int J Behav Med. 2013;20:131-9.

109. Ayub M, Mushtaq I, Mushtaq S, Hafeez MA, Helal N, Irfan M, Hassan B, Tiffin $P$, Naeem F. Domestic violence, mental illness and suicidal ideation-a study from Lahore, Pakistan. J Ment Health. 2013;22:474-81.

110. Raza MS, Jaffery SA, Khan FA. Flexor zone 5 cut injuries: emergency management and outcome. J Coll Physicians Surg Pak. 2014;24:194-7.

111. Shaikh MA. Prevalence and correlates of suicidal expression among school attending adolescents in Pakistan. J Pak Med Assoc. 2014;64:99-100.

112. Salman S, Idrees J, Hassan F, Idrees F, Arifullah M, Badshah S. Predictive factors of suicide attempt and non-suicidal self-harm in emergency department. Emergency. 2014;2:166

113. Saaiq M, Ashraf B. Epidemiology and outcome of self-inflicted burns at Pakistan Institute of Medical Sciences, Islamabad. Plast Reconstr Surg. 2014 Jul;:3:107.

114. Osama M, Islam MY, Hussain SA, Masroor SM, Burney MU, Masood MA, Menezes RG, Rehman R. Suicidal ideation among medical students of Pakistan: a cross-sectional study. J Forensic Legal Med. 2014;27:65-8.

115. Shagufta S, Boduszek D, Dhingra K, Kola-Palmer D. Criminal social identity and suicide ideation among Pakistani young prisoners. Int J Prison Health. 2015;11:98-107.
116. Rao S, Shah N, Jawed N, Inam S, Shafique K. Nutritional and lifestyle risk behaviors and their association with mental health and violence among Pakistani adolescents: results from the National Survey of 4583 individuals. BMC Public Health. 2015;15:431.

117. Asad N, Karmaliani R, Sullaiman N, Bann CM, McClure EM, Pasha O, Wright LL, Goldenberg RL. Prevalence of suicidal thoughts and attempts among pregnant Pakistani women. Acta Obstet Gynecol Scand. 2010;89:1545-51.

\section{Submit your next manuscript to BioMed Central and we will help you at every step:}

- We accept pre-submission inquiries

- Our selector tool helps you to find the most relevant journal

- We provide round the clock customer support

- Convenient online submission

- Thorough peer review

- Inclusion in PubMed and all major indexing services

- Maximum visibility for your research

Submit your manuscript at www.biomedcentral.com/submit
C Biomed Central 